\title{
Flora das cangas da Serra dos Carajás, Pará, Brasil: Commelinaceae
}

\author{
Flora of the cangas of the Serra dos Carajás, Pará, Brazil: Commelinaceae
}

Lidyanne Yuriko Saleme Aona ${ }^{1,3}$, Grênivel Mota da Costa $^{1}$ \& Maria do Carmo E. do Amaral ${ }^{2}$

\begin{abstract}
Resumo
Este estudo apresenta a descrição detalhada, ilustração e comentários morfológicos das nove espécies de Commelinaceae registradas para as cangas da Serra dos Carajás, no estado do Pará: Commelina benghalensis, C. erecta, C. obliqua, C. rufipes, Dichorisandra hexandra, D. villosula, Floscopa peruviana, Murdannia nudiflora e Tripogandra diuretica.
\end{abstract}

Palavras-chave: Commelina, espécies ameaçadas, Pará, taxonomia.

\begin{abstract}
This study provides detailed descriptions, illustrations, and morphological comments of the nine species of Commelinaceae registered for the cangas of Serra dos Carajás, Pará state: Commelina benghalensis, C. erecta, C. obliqua, C. rufipes, Dichorisandra hexandra, D. villosula, Floscopa peruviana, Murdannia nudiflora, and Tripogandra diuretica.
\end{abstract}

Key words: Commelina, threatened species, Pará state, taxonomy.

\section{Commelinaceae}

Commelinaceae engloba cerca de 41 gêneros e 650 espécies distribuídas desde regiões tropicais a regiões temperadas (Faden 1998). No Brasil, são encontrados 14 gêneros e 85 espécies, sendo Dichorisandra J.C. Mikan, Commelina L. e Tradescantia L. os mais representados. A família apresenta ampla variação nos caracteres vegetativos e, principalmente, na morfologia floral e da inflorescência (Faden 1998). Apesar de toda diversidade morfológica, a família é reconhecida pelo hábito herbáceo, lâminas foliares com bainha fechada e pelas flores geralmente efêmeras e deliquescentes (Faden 1998). Dos 13 gêneros e 27 espécies reportadas para o Domínio Fitogeográfico Amazônico, oito gêneros e 17 espécies são encontradas no Pará (BFG 2015). Destas, quatro gêneros e nove espécies ocorrem na Serra dos Carajás.

\section{Chave de identificação de gêneros de Commelinaceae das cangas da Serra dos Carajás}

1. Ervas escandentes ou raro eretas, quando eretas, apresentam os ramos apicais pendentes; flores bissexuadas e estaminadas; anteras muito mais longas que os filetes, deiscência poricida 2. Dichorisandra

1'. Ervas eretas ou prostradas a decumbentes; flores bissexuadas; anteras 3 a 4 vezes mais curtas que os filetes, deiscência rimosa

2. Erva até $30 \mathrm{~cm}$ alt., lâminas foliares lineares; cápsulas globosas, ca. $3 \mathrm{~mm}$ compr.; sementes ca. $1 \mathrm{~mm}$ compr. 4. Murdannia

2'. Erva acima de $30 \mathrm{~cm}$ alt., lâminas foliares elípticas a lanceoladas; fruto indeiscente ou cápsulas estreitamente elípticas, oblongas, 10-25 mm compr.; sementes 1,5-10 mm compr.

3. Inflorescência subtendida e envolvida por brácteas espatáceas; estames férteis 3, estaminódios 3.

3'. Inflorescência subtendida e envolvida por brácteas foliáceas; estames férteis 6 , estaminódios ausentes

\footnotetext{
${ }^{1}$ Universidade Federal do Recôncavo da Bahia, Centro de Ciências Agrárias, Ambientais e Biológicas, R. Rui Barbosa 710, Centro, 44380-000, Cruz das Almas, BA, Brasil. grenivel@gmail.com.

${ }^{2}$ Universidade Estadual de Campinas - UNICAMP, Inst. Biologia, Depto. Biologia Vegetal, C.P. 6109, 13083-970, Campinas, SP, Brasil. volker@unicamp.br

${ }^{3}$ Autor para correspondência: lidyanne.aona@gmail.com
} 
4. Sépalas glabras; pétalas róseas

5. Tripogandra

4'. Sépalas com longos tricomas glandulares, pétalas alvas 3. Floscopa

\section{Commelina L.}

Commelina é o gênero mais diverso de Commelinaceae, com 170 espécies e distribuição cosmopolita (Faden 1998). No Brasil, são encontradas 10 espécies, distribuídas em todos os estados e vários tipos de vegetação (BFG 2015). Apesar de algumas espécies do gênero serem consideradas como plantas ruderais (Souza \& Lorenzi 2012), uma espécie recém-descrita encontra-se ameaçada de extinção (Hassemer et al. 2016). Commelina difere das demais Commelinaceae por apresentar um conjunto de caracteres, como as inflorescências terminais ou opostas à lâmina foliar, composta de 1 ou 2 cincinos envoltos por bráctea espatácea e flores zigomorfas, com uma das pétalas reduzida (Faden 1998). Na Serra dos Carajás, foram encontradas quatro espécies: Commelina benghalensis L., Commelina obliqua Vahl, Commelina erecta L. e Commelina rufipes Seub.

\section{Chave para identificação de espécies de Commelina das cangas da Serra dos Carajás}

1. Margem da bainha foliar glabra a esparsamente pilosa, tricomas acastanhados; presença de aurícula inconspícua na junção com a lâmina foliar.

1.2. Commelina erecta

1'. Margem da bainha foliar com tricomas avermelhados ou ferrugíneos, raro alvos; aurícula ausente na junção com a lâmina foliar

2. Pétalas azuis, a inferior reduzida, esbranquiçada; frutos deiscentes, acastanhados, opacos

3. Lâminas foliares lanceoladas, tricomas escabros em ambas as faces; cápsula oblonga .........

1.3. Commelina obliqua

3'. Lâminas foliares elípticas a ovais, pubérulas em ambas as faces e na margem da lâmina foliar; cápsula estreitamente elíptica. 1.1. Commelina benghalensis

2'. Pétalas alvas, frutos indeiscentes, alvos ou prateados, brilhantes

4. Lâminas foliares e bainhas densamente cobertas por tricomas ferrugíneos 1.4.1. Commelina rufipes var. rufipes

4'. Lâminas foliares e bainhas glabras, exceto por linha de tricomas ferrugíneos na região oposta à inserção foliar 1.4.2. Commelina rufipes var. glabrata

1.1 Commelina benghalensis L., Sp. Pl. 41. 1753.

Erva decumbente, até $30 \mathrm{~cm}$ alt.. Caule esparsopiloso. Folhas dísticas, sésseis a pecioladas, bainhas $1-1,3 \mathrm{~cm}$ compr., pilosas, tricomas avermelhados na margem, raro alvos, tricomas 4-5 mm compr., aurícula ausente; lâminas ovais a elípticas, 3,8-9 $\times 1,6-3,5 \mathrm{~cm}$, base assimétrica, ápice agudo, pubérulas em ambas as faces, pilosas nas nervuras centrais, margem ciliada. Inflorescências 2-4, agrupadas no ápice dos ramos, eretas, 2-3 cincinos com 2-3 flores, pedúnculo $0,5-1 \mathrm{~cm}$ compr.; bráctea espatácea pedunculada, pilosa com maior concentração na parte central, bordas dorsais fechadas, margem ciliada. Flores bissexuadas, pediceladas; sépalas ovais, glabras; pétalas azuis, as 2 superiores unguiculadas, $0,4-0,4 \mathrm{~mm}$ compr., a inferior reduzida, esbranquiçada; estames 3 , anteras azuladas, elipsoides, estaminódios 3 , anteroides amarelos, cruciformes; ovário globoso, glabro, estilete $4 \mathrm{~mm}$ compr. Cápsula oblonga, 2,5-5 × 0,8$3,4 \mathrm{~mm}$, acastanhada, opaca. Sementes obovoides, 2/lóculo, 2-3 × 1-1,9 mm, acinzentadas, rugosas a foveoladas.

Material selecionado: Canaã dos Carajás, ADA Usina S11 D, margem da estrada, 06 $24^{\prime} 51^{\prime \prime} \mathrm{S}, 50^{\circ} 14^{\prime} 47^{\prime}$ 'W, 30.I.2012, fl., L.F.A. de Paula et al. 524 (BHCB).

Material adicional: BRASIL. CEARÁ: Fortaleza, Campo da Escola de Agronomia do Ceará, Bairro Alagadiç̧o, na parede de açude. 15.V.1939. P. Bezerra 65 (HURB, EAC).

Commelina benghalensis é uma erva subespontânea, quase cosmopolita e amplamente distribuída na região paleotropical (Faden 1992). No Brasil, é infestante em lavouras e ocorre em áreas alagadas e terrenos baldios (Lorenzi 2000). Apresenta como características diagnósticas as lâminas foliares elípticas a ovais finamente pubescentes, bainhas com margem ciliada, apresentando tricomas avermelhados, além 
de ser a única espécie do gênero a apresentar flores cleistógamas subterrâneas. Apesar de ser considerada uma espécie invasora, foi coletada somente uma vez na Serra de Carajás.

É amplamente distribuída no Brasil. Na Serra dos Carajás ocorre na Serra Sul: S11-D. A espécie foi coletada em margem da estrada.

\subsection{Commelina erecta L., Sp. Pl. 1: 41. 1753.}

Erva decumbente ou ereta, até $40 \mathrm{~cm}$ alt. Caule glabro. Folhas dísticas, subsésseis, bainhas $1-2 \mathrm{~cm}$ compr., glabras, margem glabra a esparsamente pilosa, tricomas acastanhados na margem, presença de aurícula na junção com a lâmina foliar; lâminas lineares a lanceoladas, 3-9 $\times 0,6-1,8 \mathrm{~cm}$, base assimétrica, ápice acuminado, glabras em ambas as faces, margem glabra. Inflorescências 2-4, agrupadas no ápice dos ramos, eretas, 2-4 cincinos com 2-4 flores, pedúnculo 1-2 cm compr.; bráctea espatácea pedunculada, glabra a esparso pilosa na base, bordas dorsais fechadas, margem glabra. Flores bissexuadas, pediceladas; sépalas ovais, glabras; pétalas azuis, as 2 superiores unguiculadas, $5 \times 4 \mathrm{~mm}$ compr., a inferior reduzida, esbranquiçada; estames 3 , anteras azuladas, elipsoides, estaminódios 3, anteroides amarelos, cruciformes; ovário globoso, glabro, estilete $4 \mathrm{~mm}$ compr. Cápsula oblonga, 3-5 3 mm, castanha, brilhante. Sementes imaturas, $2 \times 2 \mathrm{~cm}$.

Material selecionado: Canaã dos Carajás, Serra Sul, 06 23'49”'S, 50²0'57'”, 06.XII.2007, fl., P.L. Viana et al. 3346 (BHCB); Serra Sul, Corpo D, 06 $24^{\prime} 31^{\prime \prime} \mathrm{S}$, $50^{\circ} 19^{\prime} 07^{\prime}$ 'W, 18.V.2010, fl., M.O. Pivari et al. 1506 (BHCB).

Apesar de apresentar uma grande variação morfológica, Commelina erecta pode ser facilmente identificada pela presença das brácteas conatas na margem posterior e por ser a única espécie a apresentar a base da lâmina foliar auriculada na junção com a bainha, característica não vista em outras espécies brasileiras. No Brasil, é considerada planta infestante em pomares, lavouras e terrenos baldios (Lorenzi 2000).

Esta espécie apresenta distribuição cosmopolita e pode ocorrer em áreas antropizadas e borda de mata. Na Serra dos Carajás ocorre na Serra Sul: S11-D, em Floresta Ombrófila e em área alagada vegetação sobre canga.

1.3. Commelina obliqua Vahl, Enum. Pl. 2: 172. 1805.

Erva ereta, até $55 \mathrm{~cm}$ alt. Caule glabro. Folhas dísticas, subsésseis, bainhas $1,7-2,5 \mathrm{~cm}$ compr., glabras, margem ciliada, tricomas avermelhados na margem, aurícula ausente na junção com a lâmina foliar; lâminas lanceoladas, 5-9,2 × 1-2 cm, base assimétrica, ápice acuminado, tricomas escabros em ambas as faces, margem glabra. Inflorescências 2-4, agrupadas no ápice dos ramos, eretas, ca. 2-4 cincinos com 2-4 flores, pedúnculo 1-2 cm compr.; bráctea espatácea pedunculada, glabras a esparso pilosas na base, bordas dorsais fechadas, margem glabra. Flores bissexuadas, pediceladas; sépalas ovais, glabras; pétalas azuis, as 2 superiores unguiculadas, $5 \times 4 \mathrm{~mm}$ compr., a inferior reduzida, esbranquiçada; estames 3, anteras azuladas, elipsoides, estaminódios 3, anteroides amarelos, cruciformes; ovário globoso, glabro, estilete $4 \mathrm{~mm}$ compr. Cápsula estreitamente elíptica, castanha, opaca. Sementes obovoides, base truncada, $5 \times 3$ $\mathrm{mm}$, castanho, rugosas.

Material selecionado: Canaã dos Carajás, S11-D, 06²3'55'S, 50¹6'39'W, 04.VIII.2010, fr., L.V. Costa 1020 (BHCB); Parauapebas, Serra Sul, Corpo D, $06^{\circ} 23^{\prime} 46^{\prime}$ 'S, 50¹6’39”'W, 17.III.2009, fl., P.L. Viana et al. 4125 (BHCB).

Commelina obliqua apresenta como características principais as lâminas escabras e a bráctea espatácea com bordas dorsais fechadas, envolvendo dois cincinos: um incluso e outro exserto (Aona \& Amaral 2009), além dos tricomas avermelhados na região oposta à inserção foliar.

Ocorre nas Américas Central e do Sul, Costa Rica, Nicarágua, México, Argentina e Trinidad (Hunt 1994; Hunt 2001; Grant et al. 2003). Apresenta ampla distribuição no Brasil, ocorrendo do norte ao sul do país (Barreto 1997). Na Serra dos Carajás ocorre na Serra Sul: S11-D, em Floresta Ombrófila e a locais próximos a buritizal.

1.4.1. Commelina rufipes Seub. var. rufipes, in Mart., Fl. bras. 3(1): 266. $1855 . \quad$ Fig. 1a-c Erva decumbente, até $30 \mathrm{~cm}$ alt. Caule pubérulo. Folhas dísticas, subsésseis, bainhas 1,3-1,8 cm compr., densamente pilosas, margem ciliada, tricomas ferrugíneos, aurícula ausente na junção com a lâmina foliar; lâminas lanceoladas, $6,5-11,5 \times 1,6-2,8 \mathrm{~cm}$, base assimétrica, ápice acuminado, densamente pilosas em ambas as faces, tricomas curtos, 1-1,5 mm compr., alvos a acastanhados, margem curto-ciliada no terço apical. Inflorescências 1-2, agrupadas no ápice e ramos laterais, eretas, 2-3 cimeiras com 4-5 flores, pedunculadas; bráctea espatácea pedunculada, cimbiforme, curto-pilosa, tricomas ferrugíneos, bordas dorsais fechadas, margem ciliada. Flores 


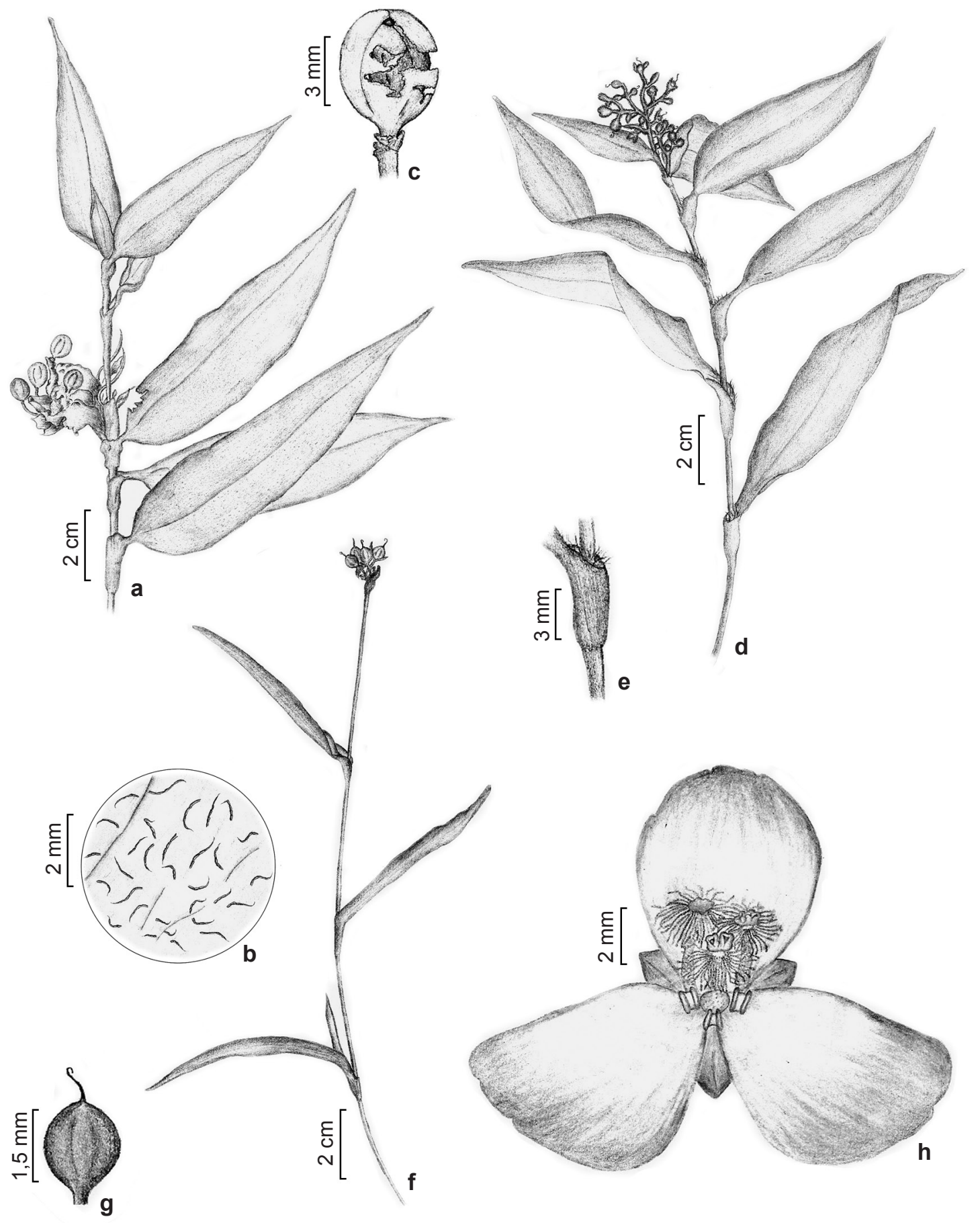

Figura 1 - a-c. Commelina rufipes var. rufipes - a. hábito; b. detalhe dos tricomas da face adaxial da lâmina foliar; c. fruto maduro. d-e. Floscopa peruviana - d. hábito; e. detalhe da bainha. f-g. Murdannia nudiflora -f. hábito; g. detalhe do fruto. h. Tripogandra diuretica - detalhe da flor. (a-c. L.C.B. Lobato 4197; d-e. F.D. Gontijo 193; f-g. M.O. Pivari et al. 1680; h. J.P. Silva 417)

Figure 1 - a-c. Commelina rufipes var. rufipes - a. habit; b. detail of trichomes of the adaxial leaf side; c. fruit. d-e. Floscopa peruviana - d. habit; e. detail of the sheath. f-g Murdannia nudiflora-f. habit; g. detail of the fruit. h. Tripogandra diurética-detail of the flower. (a-c. L.C.B. Lobato 4197; d-e.F.D. Gontijo 193; f-g. M.O. Pivari et al. 1680; h. J.P. Silva 417) 
bissexuadas, pediceladas; sépalas ovais, glabras; pétalas brancas, as 2 superiores ungüiculadas, a inferior linear; estames 3, anteras amarelas, elipsoides, estaminódios 3, anteroides amarelos, cruciformes; ovário elipsoide, glabro. Fruto indeiscente, ovoide a globoso, ca. 1-1,2 × 1 cm, alvo, brilhante. Sementes elipsoides, 1/lóculo, $10 \times 5 \mathrm{~mm}$, acinzentadas.

Material selecionado: Parauapebas, Serra dos Carajás, Igarapé Baia (projeto Alemão), 23.VI.2013, fr., L.C.B. Lobato et al. 4197 (MG).

Espécie facilmente reconhecida pelo conjunto de caracteres como a presença de lâminas foliares e bainha densamente cobertas por tricomas ferrugíneos, flores alvas e frutos indeiscentes alvos e brilhantes. Tem ampla distribuição, ocorrendo na Costa Rica, Argentina, Nicarágua, Trinidade e Tobago (Barreto 1997; Grant et al. 2003; Hunt 1994, 2001). Na Serra dos Carajás ocorre, em Floresta Ombrófila ou floresta alterada.

1.4.2. Commelina rufipes var. glabrata (D.R. Hunt) Faden \& D.R. Hunt in Ann. Missouri Bot. Gard., 74(1): 122. 1987.

Erva decumbente, até $30 \mathrm{~cm}$ alt. Caule glabro. Folhas dísticas, subsésseis, bainhas 1,1-1,5 cm compr., glabras a não ser por uma linha de tricomas ferrugíneos na região oposta à inserção foliar, margem ciliada, tricomas ferrugíneos, aurícula ausente na junção com a lâmina foliar; lâminas foliares lanceoladas, 7-11,5 × 1,5-2,8 cm, base assimétrica, ápice acuminado, glabras em ambas as faces, margem glabra. Inflorescências 2, agrupadas no ápice dos ramos, eretas, 2 cimeiras com 1-3 flores, pedunculadas; bráctea espatácea pedunculada, cimbiforme, glabras, bordas dorsais fechadas, margem ciliada na base. Flores bissexuadas, pediceladas; sépalas ovais, glabras; pétalas brancas, as 2 superiores unguiculadas, a inferior linear; estames 3, anteras amarelas, elipsoides, estaminódios 3, anteroides amarelos, cruciformes; ovário elipsoide, glabro, liso. Fruto indeiscente, oval a globoso, ca. 1,1 × 1,1 cm, alvo a prateado, brilhante. Sementes elipsoides, 8-10 $\times$ 4-5 mm, 1/lóculo, acinzentadas.

Material selecionado: Canaã dos Carajás, Floresta Nacional de Carajás: Serra Sul, corpo A, 06¹8'33'S, 50²7'19'W, 29.VI.2010, fr., T.E. Almeida et al. 2438 (BHCB).

Commelina rufipes var. rufipes e C. rufipes var. glabrata compartilham a mesma característica de presença de flores alvas e frutos alvos e brilhantes, porém C. rufipes var. rufipes difere de C. rufipes var. glabrata por apresentar lâminas foliares e bainhas glabras.

Subespécie com distribuição na Bolívia, Colômbia, Guiana, Guiana Francesa, Peru, Suriname, Venezuela e Nicarágua (Barreto 1997; Hunt 1994, 2001). Na Serra dos Carajás ocorre na Serra Sul: S11A, em borda de brejo.

\section{Dichorisandra J.C. Mikan}

Com distribuição neotropical, Dichorisandra é o principal gênero de Commelinaceae no Brasil, onde ocorrem 41 espécies, das quais 30\% foram descritas na última década (Maia et al. 2006; Aona \& Amaral 2012; Aona et al. 2012, 2014, 2016), estando a maioria ameaçada de extinção. Ocorrem predominantemente em florestas úmidas, sendo a Floresta Atlântica o centro de diversidade do gênero (Aona 2008), mas também encontradas em formações campestres e restingas. Apesar de exibirem hábitos diversos, as espécies de Dichorisandra são facilmente reconhecidas pelas sementes ariladas, anteras mais longas que os filetes e, na maioria das espécies, anteras com deiscência poricida (Faden \& Hunt 1991; Aona 2008).

\section{Chave para identificação de espécies de Dichorisandra das cangas da Serra dos Carajás}

1. Ervas escandentes; lâmina foliar com ambas as faces glabras ou face adaxial com raros tricomas, principalmente na base. 2.1. Dichorisandra hexandra

1'. Ervas escandentes ou raro eretas, quando eretas, às vezes com ramos apicais pendentes; face adaxial glabra, face abaxial da lâmina foliar com indumento uniformemente distribuído, densamente piloso 2.2. Dichorisandra villosula

2.1. Dichorisandra hexandra (Aubl.) C.B. Clarke, Bull. Torrey Bot. Club 29(2): 703. 1902.

Fig. 2a-d

Ervas escandentes, até 1,5 m alt. Caule glabro ou com tricomas. Folhas dísticas, alternas, bainha 1-2,1 cm compr., glabras, margem ciliada; pecíolo 1-2 mm compr., pubérulo; lâminas linearlanceoladas, lanceoladas, 5-10,5 × 0,5-2,5 cm, base simétrica ou assimétrica, ápice acuminado, margem curto-ciliada, ambas as faces glabras ou face adaxial pubérula na base. Inflorescência ereta; pedúnculo 1-2,5 cm compr., curto-piloso; 

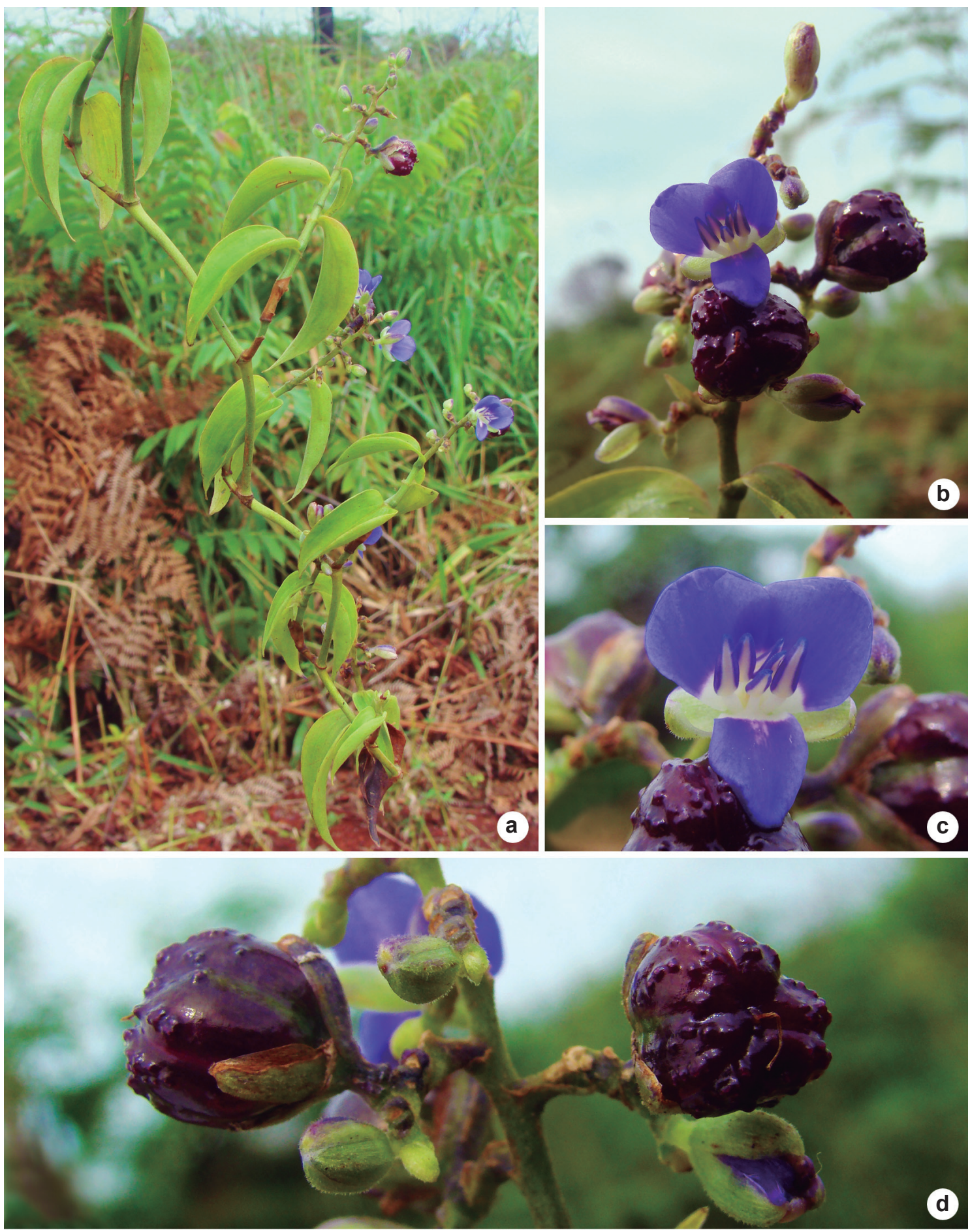

Figura 2 - a-d. Dichorisandra hexandra - a. hábito escandente; b. detalhe da inflorescência no ápice do ramo; c. detalhe da flor estaminada evidenciando os 6 estames com anteras alvas com os sacos polínicos azuis; d. detalhe dos frutos evidenciando a coloração vinácea, quase enegrecida (N.F.O. Mota 2963).

Figure 2 - a-d. Dichorisandra hexandra. - a. vine habit; b. detail of inflorescence at the apex of the stem; c. detail of staminate flower showing the 6 stamens with white anthers and bluish pollen sac; d. detail of fruits with dark bordeaux, almost black colour (N.F.O. Mota 2963). 
pedúnculo dos cincinos 3-4 mm compr., 6-11 cincinos não muito congestos, 3-6 flores; brácteas dos cincinos 5-8 $\times 1 \mathrm{~mm}$, face abaxial curto-pilosa, margem ciliada; bractéolas ca. 1 x $1 \mathrm{~mm}$. Flores estaminadas e bissexuadas, zigomorfas; pedicelo 1-3 mm compr., curto-piloso; sépalas elípticas a ovais, 6-8 × 3-4 mm, glabras ou curto-pilosas; pétalas obovais, azuis-arroxeadas, base alva, 7 $\times 4 \mathrm{~mm}$; estames 6 , anteras alvas com os sacos polínicos azuis, $4-5 \mathrm{~mm}$ compr., 2 poros apicais; ovário globoso, 3-locular glabro, 2-3 × 2-3 mm. Cápsula submadura globosa, $6-7 \times 7-8 \mathrm{~mm}$, violeta a enegrecida. Sementes elipsoides a ovoides, $4-6 \times$ $3 \mathrm{~mm}$, ca. 4/lóculo, arilo alaranjado.

Material selecionado: Canaã dos Carajás, S11-D; 06²3'55'S, 50¹6'39”'W, 17.III.2009, fr., P.L. Viana 4099 (BHCB, MG); Serra Sul, Corpo C, 06²3'54'S, 50²1'59'W, 19.II.2010, fl., F.D. Gontijo 131 (BHCB); Serra Sul, Corpo A, 06 22’34'S, 50²3' 6”'W, 13.II.2010, fl., F.D. Gontijo 36 (BHCB); Marabá, Serra dos Carajás, N-4, 19.III.1984, fl. e fr. L.S.A. Silva et al. 1889 (UFMT); Parauapebas, N4WS, 06 04 '23'S, 50 $0^{\circ} 11^{\prime} 31^{\prime \prime} \mathrm{W}$, 24.III.2012, fl., P.B. Meyer et al. 1193 (BHCB).

Dichorisandra hexandra é uma erva escandente e apresenta como característica principal a presença de flores azuis com seis estames com anteras deiscentes por 2 poros apicais e sementes com arilo alaranjado, além apresentar lâminas foliares glabras ou com tricomas apenas com a face adaxial. É a espécie com maior distribuição do gênero e ocorre, preferencialmente, em Floresta Ombrófila Densa Atlântica, em Floresta Estacional Semidecidual e na Floresta Ombrófila Densa Amazônica (Aona 2008).

Espécie de distribuição Neotropical, sendo encontrada na Argentina, Bolívia, Colômbia, Costa Rica, Equador, El Salvador, Guiana Francesa, Guatemala, Panamá, Paraguai, Peru, Suriname, Venezuela. No Brasil, está presente em todas as regiões (Barreto 1997; Aona \& Leoni 2006; Aona 2008). Na Serra dos Carajás foi encontrada na Serra Norte: N4; Serra Sul: S11-A, C, e D e Serra da Bocaina em mata em regeneração de Floresta Ombrófila, em mata entre lagoas, capão de mata, mata de terra firme, em solo de canga.

2.2. Dichorisandra villosula Mart. ex Schult.f. in Schultes \& Schultes f., Syst. veg. 7(2): 1185. 1830.

Ervas escandentes ou a raro eretas, quando eretas, podem apresentar ramos apicais pendentes, até $0,6 \mathrm{~cm}$ alt. Caule densamente piloso. Folhas dísticas, alternas, bainha $1-2,5 \mathrm{~cm}$ compr., pilosa, margem ciliada; pecíolo 1-1,5 mm compr., pubérulo; lâminas lanceoladas, 9-17 × 1-3,5 cm, base assimétrica, ápice acuminado, margem curto-ciliada, face adaxial glabra, face abaxial uniformemente pilosa. Inflorescência ereta; pedúnculo $1-2 \mathrm{~cm}$ compr., piloso; pedúnculo dos cincinos 5-6 mm compr., 7-15 cincinos não muito congestos com 4-6 flores; brácteas dos cincinos $20 \times 1 \mathrm{~mm}$, ambas as faces pilosas, margem ciliada; bractéolas 1-2 × 1-2 mm. Flores estaminadas e bissexuadas, zigomorfas; pedicelo $2-4 \mathrm{~mm}$ compr., piloso; sépalas elípticas a ovais, 6-8 × 3-4 mm, pilosas; pétalas obovais a ovais, azuis-arroxeadas, base alva, $7 \times 4 \mathrm{~mm}$; estames 6 , anteras alvas com os sacos polínicos azuis, $4-5 \mathrm{~mm}$ compr., 2 poros apicais; ovário globoso, 3-locular, 2-3 × 2-3 mm. Cápsula submadura globosa, 6-7×6-7 mm, violeta a enegrecida. Sementes ovoides a piramidais, $4-6 \times$ $3 \mathrm{~mm}$, ca. 3/lóculo, arilo alaranjado.

Material selecionado: Serra dos Carajás, Parauapebas, Igarapé Bahia, Estrada do Pojuca, 27.XI.2013, fl. e fr., L.C.B. Lobato et al. 4273 (MG); Serra dos Carajás, N5, vegetação de canga, 27.II.2012, fl. e fr., P.P. Chaves et al. 05 (MG).

Dichorisandra villosula é muito semelhante a $D$. hexandra em relação à morfologia floral, por apresentar 6 estames com anteras de deiscência poricida. Porém, D. villosula pode ser diferenciada de $D$. hexandra na Serra de Carajás pela presença de indumento piloso na face abaxial da lâmina, bainha e sépalas. Ocorre em Floresta Ombrófila Densa Amazônica (Aona 2008).

Espécie de ampla distribuição, sendo encontrada na América do Sul na Bolívia, Colômbia, Equador, Peru, Venezuela e Suriname. No Brasil, é encontrada no Acre, Amazonas, Distrito Federal, Goiás, Minas Gerais, Mato Grosso, Roraima, Pará, Rondônia e Tocantins (Aona 2008). Na Serra dos Carajás ocorre na Serra Norte: N5 em floresta alterada com cipó.

\section{Floscopa Lour.}

Gênero pantropical com 20 espécies (Faden 1998; Faden \& Hunt 1991). No Brasil, ocorrem 4 espécies distribuídas em todos os domínios fitogeográficos e formações vegetacionais, sendo um dos gêneros associados a locais úmidos ou a ambientes aquáticos. São facilmente reconhecidas pelo androceu assimétrico e sépalas mais largas que as pétalas (Evans et al. 2000). Na Serra dos Carajás foi encontrada apenas uma espécie.

3.1. Floscopa peruviana Hassk. ex C.B. Clarke, Monogr. Phan. [A.DC. \& C.DC.] 3: 270. 1881.

Fig. 1d-e

Ervas prostradas, ramos apicais eretos, até 30 $\mathrm{cm}$ alt. Caule glabro. Folhas alternas, espiraladas, 
bainhas 1,3-1,5 cm compr., glabras, margem ciliada com tricomas septados, acastanhados; pecíolo $2 \mathrm{~mm}$ compr.; lâminas lanceoladas, 8,5-12,3 × $1,6-2 \mathrm{~cm}$, base simétrica, ápice acuminado, ambas as faces glabras, margem ciliada. Inflorescência ereta, pedúnculo 1,4-4,2 cm compr., piloso, tricomas septados; $10-11$ cincinos mais ou menos congestos com 3-4 flores; pedúnculo dos cincinos 2-3 mm compr.; brácteas dos cincinos $25 \times 5$ $\mathrm{mm}$, glabras, margem ciliada; bractéolas 2-3× $1 \mathrm{~mm}$. Flores bissexuadas, zigomorfas; pedicelo 1-2 mm compr., tricomas septados; sépalas ovais, pilosas, tricomas septados, ca. $2 \times 1 \mathrm{~mm}$; pétalas ovais, alvas, ca. $3 \times 2 \mathrm{~mm}$; estames 6 , desiguais; ovário globoso, 2-locular, ca. $1 \times 1 \mathrm{~mm}$, estilete 4-5 mm compr. Cápsula achatada, levemente discoide, acastanhada, brilhante, $2 \times 2,5-3 \mathrm{~mm}$. Semente elipsoide, ca. 1/lóculo, ca. 1,5 × 1,5 mm, acastanhada, farinácea, costada.

Material selecionado: Canaã dos Carajás, Racha Placa; $06^{\circ} 25^{\prime} 18^{\prime}$ 'S, $50^{\circ} 16^{\prime} 56^{\prime}$ 'W, 29.VI.2010, fl. e fr., F.D. Gontijo 193 (BHCB).

Esta espécie pode ser identificada por apresentar bainha, pedúnculo da inflorescência, pedicelo e sépalas com tricomas segmentados, normalmente de coloração castanha.

Ocorre no domínio fitogeográfico Amazônia. No Brasil, ocorre na região Norte e Centro Oeste (Mato Grosso). Na Serra dos Carajás foi coletada no Racha Placa, na beira de córrego.

\section{Murdannia Royle}

O gênero Murdannia é pantropical, representado por 54 espécies, tendo a Índia como seu centro de diversidade (Govaerts \& Faden 2011). No Brasil, o gênero está distribuído por quase todos os estados e domínios fitogeográficos (exceto Pampa), ocorrendo quatro espécies, sendo duas endêmicas. Somente Murdannia nudiflora (L.) Brenan foi encontrada na Serra dos Carajás.

\subsection{Murdannia nudiflora (L.) Brenan, Kew Bull.} 7: 189. 1952.

Fig. 1f-g.

Ervas eretas ou prostradas, cespitosas, 20-30 cm alt. Caule glabro, enraizando nos nós. Folhas subamplexicaules, espiraladas, bainhas 3-5 mm compr., glabras ou com tricomas na base, margem esparsamente ciliada, tricomas castanhos, septados; lâminas lineares, 3-10 × 3-5 cm, ápice agudo, ambas as faces glabras, margem glabra. Inflorescência terminal, ereta, cimas solitárias com 5-10 flores; pedúnculo 2-14 cm compr., glabro; bráctea 1 , hialina, $3 \times 5 \mathrm{~mm}$, margem glabra, às vezes caduca. Flores bissexuadas, ligeiramente zigomorfas, pediceladas; pedicelo $2-5 \mathrm{~mm}$ compr., glabro; sépalas ovais, iguais, livres; pétalas ovais, subiguais, livres, lilases; estames 2 , filetes barbados, estaminódios 4, um com filete barbado, 3 com filete glabro; estilete $3 \mathrm{~mm}$ compr., alargado. Cápsulas maduras globosas, 3-4 × 2-3 mm, apiculadas, castanho-claras, brilhantes. Sementes triangulares, $2 \times 1,5 \mathrm{~mm}, 2 /$ lóculo, acastanhadas, foveoladas.

Material selecionado: Canaã dos Carajás, segundo aceiro à direita da área da Pilha de Estéril S11D, $06^{\circ} 27^{\prime} 11,58^{\prime \prime}$ 'S 50²0'55”W, 10.XII.2012, fl. e fr., M.O. Pivari et al. 1680 (BHCB, MG).

Murdannia nudiflora é uma erva delicada e pode ser caracterizada pelos pedúnculos glabros, cimeiras curtas, unilaterais e por apresentar flores diminutas e lilases (Grant et al. 2003). É considerada uma espécie infestante, ocorrendo principalmente no Centro Oeste, porém já aumentando consideravelmente sua distribuição no Brasil (Lorenzi 2000).

Espécie nativa da Ásia tropical, introduzida no sudeste dos Estados Unidos, México até Antilhas, Costa Rica, Suriname e Brasil (Grant et al. 2003). Na Serra dos Carajás ocorre na Serra Sul: S11-D em área florestal antropizada próxima a pastagem, associada a córrego ou em brejo.

\section{Tripogandra Raf.}

O gênero Tripogandra apresenta 36 espécies com distribuição neotropical, das quais 7 são registradas para o Brasil (Handlos 1975). Espécies de Tripogandra ocorrem principalmente em florestas estacionais deciduais e semideciduais, em áreas de cerrado associadas às matas de galeria (BFG 2015). São facilmente reconhecidas pelas flores zigomorfas, estames dimórficos e brácteas do cincino vestigiais. Na Serra dos Carajás foi encontrada apenas Tripogandra diuretica (Mart.) Handlos.

5.1. Tripogandra diuretica (Mart.) Handlos, Rhodora 77: 259. $1975 . \quad$ Fig. 1f

Ervas perenes, prostradas a eretas, até 40 $\mathrm{cm}$ alt. Caule glabro. Folhas sésseis, dísticas, alternas, bainha $0,5-1,2 \mathrm{~cm}$ compr., geralmente glabra, margem ciliada; lâminas lanceoladas, $5,2-9,2 \times 1-1,5 \mathrm{~cm}$, base assimétrica, ápice acuminado, ambas as faces glabras, margem ciliada. Inflorescência ereta, com 4 cincinos com 4-5 flores; pedúnculo 5-6,5 cm compr., glabro; brácteas do cincinos $12 \times 3 \mathrm{~mm}$, ambas as faces glabras, 
bractéolas 2,5 × 1,2 mm. Flores bissexuadas, zigomorfas, pedicelo 2-5 mm compr.; sépalas ovais, glabras, $6 \times 3,5 \mathrm{~mm}$, pétalas obovais, róseas, $10 \times 5 \mathrm{~mm}$, estames 6 , em dois verticilos, verticilo inferior, filetes $1-2 \mathrm{~mm}$ compr., rosados, glabros, anteras rimosas, elípticas, rosadas, verticilo superior, filetes $5 \mathrm{~mm}$ compr., sigmoides, rosados, tricomas moniliformes, tricomas rosados, anteras rimosas, oblongas, amareladas, conectivo expandido; ovário globoso, 3-locular, $1 \times 1 \mathrm{~mm}$. Cápsulas obovoides, $3 \times 2 \mathrm{~mm}$, opacas. Sementes triangulares, 2/lóculo, 1,5 × $1 \mathrm{~mm}$, acinzentadas, rugosas.

Material selecionado: Parauapebas, Serra dos Carajás, proximidades da Vila de N-5, 3.VI.1989, fl., J.P. Silva 417 (MG).

Material adicional: BRASIL. SÃO PAULO. Botucatu, direção Leste $10 \mathrm{~km}$, perto da Fábrica DURATEX, 07.IV.1971, fl. e fr., I. \& G. Gottsberger 32-7471 (HURB).

Espécie amplamente variável em relação ao seu tamanho e morfologia foliar. Pode ser caracterizada pela presença de pétalas róseas e estames em dois verticilos, claramente em tamanhos e morfologias diferentes. Lorenzi (2000) considera esta espécie infestante em planícies litorâneas, ocorrendo em menor intensidade em outras regiões. Espécie associada a locais úmidos, sombreados e áreas de pastagem.

Espécie com ampla distribuição, ocorre no Brasil, Bolívia, Paraguai, Argentina, Peru, Guatemala, Panamá, México e Uruguai comumente associada a lugares úmidos (Handlos 1975; Barreto 1997). Na Serra dos Carajás ocorre na Serra Norte: N5.

\section{Agradecimentos}

Os autores agradecem aos curadores dos herbários EAC, BHCB, HURB, MG e UFMT, o acesso aos materiais; a V. Bittrich, as correções; a N.F.O. Mota, as fotos de Dichorisandra hexandra; a L.C. Marinho, a confecção da prancha de $D$. hexandra; a D. Souza, as ilustrações das espécies; e aos coordenadores do projeto "Flora de Carajás", P.L. Viana e A.M. Giulietti, o convite. Ao projeto objeto do convênio MPEG/ITV/ FADESP (01205.000250/2014-10) e ao projeto aprovado pelo CNPq (processo 455505/2014-4), o financiamento.

\section{Referências}

Aona, L.Y.S. 2008. Revisão taxonômica e análise cladística do gênero Dichorisandra J.C.
Mikan (Commelinaceae). Tese de Doutorado. Universidade Estadual de Campinas, São Paulo. 310p.

Aona, L.Y.S. \& Amaral, M.C.E. 2009. Flora da Serra do Cipó, Minas Gerais: Commelinaceae. Boletim de Botânica da Universidade de São Paulo 27: 253-258.

Aona, L.Y.S. \& Leoni, L.S. 2006. Commelinaceae. Flora Fanerogâmica do Parque Estadual do Brigadeiro. Pabstia XVII: 1-10.

Aona, L.Y.S. \& Amaral, M.C.E. 2012. Four new species of Dichorisandra J.C. Mikan (Commelinaceae) from Southeast Brazil. Phytotaxa 48: 7-22.

Aona, L.Y.S.; Faden, R.B.; Bittrich, V. \& Amaral, M.C.E. 2016. Four new species of Dichorisandra (Commelinaceae) endemic from Bahia state. Brittonia 68: 61-73.

Aona, L.Y.S.; Amaral, M.C.E. \& Bittrich, V. 2014. Two new species of Dichorisandra (Commelinaceae) from Rio de Janeiro and comments on the two species included in Vellozo's 'Flora Fluminensis'. Phytotaxa 184: 223-234.

Aona, L.Y.S.; Faden, R.B. \& Amaral, M.C.E. 2012. Five new species of Dichorisandra J.C. Mikan (Commelinaceae). Kew Bulletin 66: 1-13.

Barreto, R.C. 1997. Levantamento das espécies de Commelinaceae R.Br. nativas do Brasil. Tese de Doutorado. Universidade de São Paulo, São Paulo. 488p.

BFG. 2015. Growing knowledge: an overview of seed plant diversity in Brazil. Rodriguésia 66: 10851113.

Evans, T.M.; Faden, R.B.; Simpson, M.G. \& Sytsma, K.J. 2000. Phylogenetic relationships in the Commelinaceae: I. A. Cladistic Analysis of Morphological. Systematic Botany 25: 668-691.

Faden, R.B. 1992. Proposal to conserve Commelina benghalensis (Commelinaceae) with a conserved type under Art. 69.3. Taxon 41: 341-342.

Faden, R.B. 1998. Commelinaceae. In: Kubitzki, K. (ed.). The families and genera of vascular plants. Vol. 4. Springer Verlag, Berlin. Pp. 109-128.

Faden, R.B. \& Hunt, D.R. 1991. The Classification of the Commelinaceae. Taxon. 40: 19-31.

Govaerts, R. \& Faden, R.B. 2011. World checklist of Commelinaceae. The board of trustees of the Royal Botanic Gardens, Kew. Disponível em <http:// apps.kew.org/wcsp/home.do>. Accesso em 22 abril 2016.

Grant, J.R.; Faden, R.B. \& Hammel, B.E. 2003. Commelinaceae. In: Hammel, B.E.; Grayum, M.H.; Herrera, C. \& Zamora, N. (eds.). Manual de plantas de Costa Rica, Vol. II: Gimnospermas y Monocotiledóneas (Agavaceae-Musaceae). Missouri Botanical Garden Press, Saint Louis. Pp. 386-409. 
Handlos, W.L. 1975. The taxonomy of Tripogandra (Commelinaceae). Rhodora 70: 213-329.

Hassemer, G.; Ferreira, J.P.R.; Funez, L.A. \& Medeiros, J.D. 2016. Commelina catharinensis (Commelinaceae): a narrow endemic and endangered new species from Santa Catarina, southern Brazil. Phytotaxa 246: 49-60.

Hunt, D. 1994. Commelinaceae. In: Davidse, G.; Sousas, M.S. \& Chater, A.O. (eds.) Flora Mesoamericana. Alismataceae a Cyperaceae. Vol. 6. Missouri Botanical Garden Press, Saint Louis. Pp. 157-173.

Hunt, D. 2001. Commelinaceae. In: Stevens, W.D.; Ulloa, C.U.; Pool, A. \& Montiel, O.M. (eds.). Flora de Nicaragua. Introduccíon Gimnospermas y Angiospermas (Acanthaceae-Euphorbiaceae) 85, Tomo 1. Missouri Botanical Garden Press, Saint Louis. Pp. 638-650.

Lorenzi, H. 2000. Plantas daninhas do Brasil: terrestres, aquáticas e parasitas e tóxicas. $3^{\mathrm{a}}$ ed. Instituto Plantarum, Nova Odessa. 608p.

Maia, D.C.; Cervi, A.C. \& Tardivo, R.C. 2006. Uma nova espécie de Dichorisandra J.C. Mikan (Commelinaceae) do estado do Paraná e Santa Catarina (Brasil). Fontqueria 55: 297-300.

Souza, V.C. \& Lorenzi, H. 2012. Botânica Sistemática. Guia ilustrado para identificação das famílias de Fanerógamas nativas e exóticas no Brasil, baseado em APG III. $3^{\text {a }}$ ed. Instituto Plantarum, Nova Odessa. 768p.

\section{Lista de exsicatas}

Almeida, T.E. 2438 (1.5); Arruda, A.J. 517 (4.1), 1193 (2.1), 1218 (1.4); Bezerra, P. 65 (1.1); Chaves, P.P. 5 (2.2); Costa, L.V. 532 (1.2), 1020 (1.3); Gontijo, F.D. 36 (2.1), 131 (2.1), 162 (1.3), 193 (3.1); Gottsberger, G. 32-7471 32w(5.1); Lobato, L.C.B. 4197 (1.4), 4273 (2.2); Meyer, P.B. 1193 (2.1); Mota, N.F.O. 2603 (2.1); Paula, L.F.A. 524 (1.1); Pivari, M.O. 1506 (1.2), 1680 (4.1); Santos, R.S. 219 (2.1); Silva, J.P. 417 (5.1); Silva, L.S.A. 1889 (2.1); Viana, P.L. 3346 (1.2), 4099 (2.1), 4125 (1.3), 4395 (1.2). 